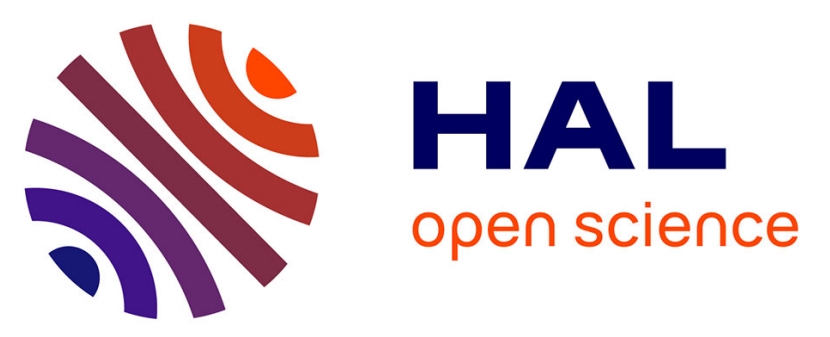

\title{
Resting energy expenditure equations in amyotrophic lateral sclerosis, creation of an ALS-specific equation
}

Pierre Jésus, Benoît Marin, Philippe Fayemendy, Marie Nicol, Géraldine

Lautrette, Huguette Sourisseau, Pierre-Marie Preux, Philippe Couratier, Jean-Claude Desport

\section{To cite this version:}

Pierre Jésus, Benoît Marin, Philippe Fayemendy, Marie Nicol, Géraldine Lautrette, et al.. Resting energy expenditure equations in amyotrophic lateral sclerosis, creation of an ALS-specific equation. Clinical Nutrition, 2018, S0261-5614 (18), pp.32385-32389. 10.1016/j.clnu.2018.08.014 • hal-01898596

\section{HAL Id: hal-01898596 \\ https://hal-unilim.archives-ouvertes.fr/hal-01898596}

Submitted on 25 Oct 2021

HAL is a multi-disciplinary open access archive for the deposit and dissemination of scientific research documents, whether they are published or not. The documents may come from teaching and research institutions in France or abroad, or from public or private research centers.
L'archive ouverte pluridisciplinaire HAL, est destinée au dépôt et à la diffusion de documents scientifiques de niveau recherche, publiés ou non, émanant des établissements d'enseignement et de recherche français ou étrangers, des laboratoires publics ou privés.

\section{(ㅇ)(1) $\$$}

Distributed under a Creative Commons Attribution - NonCommerciall 4.0 International 
1 Resting energy expenditure equations in Amyotrophic Lateral Sclerosis, creation of an

2 ALS-specific equation.

3

4 Pierre Jésus ${ }^{1,2,3^{*}}$, Benoit Marin ${ }^{2,3,4^{*}}$, Philippe Fayemendy ${ }^{1,2,3}$, Marie Nicol $^{2,3,5}$, Géraldine

5 Lautrette $^{5}$, Huguette Sourisseau ${ }^{1}$, Pierre-Marie Preux ${ }^{2,3,4}$, Philippe Couratier ${ }^{2,3,5}$, Jean-Claude

6 Desport $^{1,2,3}$.

$7 \quad *$ Both authors contributed equally to this work.

$8{ }^{1}$ Nutrition Unit, University Hospital of Limoges, 87000 Limoges, France.

$9 \quad{ }^{2}$ INSERM, U1094, Tropical Neuroepidemiology, 87000 Limoges, France.

10 3niv. Limoges, UMR_S 1094, Tropical Neuroepidemiology, Institute of Neuroepidemiology

11 and Tropical Neurology, CNRS FR 3503 GEIST, F-87000 Limoges, France.

$12{ }^{4}$ Center of Epidemiology, Biostatistics and Research Methodology (CEBIMER), University

13 Hospital of Limoges, 87000 Limoges, France.

$14{ }^{5}$ ALS center, University Hospital of Limoges, 87000 Limoges, France.

16 Corresponding author: Dr. Pierre Jésus, Nutrition Unit, University Hospital of Limoges, 2

17 Avenue Martin Luther King, 87042 Limoges cedex.

18 E-mail address: p.jesus@wanadoo.fr

19 Phone: + 33555056621

20 Fax: + 33555056354 


\section{Abstract}

Introduction: Resting energy expenditure (REE) formulas for healthy people (HP) are used to calculate REE (cREE) in amyotrophic lateral sclerosis (ALS) patients. In 50-60\% of ALS cases an increase of measured REE (mREE) in indirect calometry (IC) compared to cREE is found. The aims here were (i) to assess the accuracy of cREE assessed using 11 formulas as compared to mREE and (ii) to create (if necessary) a specific cREE formula for ALS patients. Method: 315 Patients followed in the ALS expert center of Limoges between 1996 and 2014 were included. mREE assessed with IC and cREE calculated with 11 predictive formulas (Harris Benedict (HB) 1919, HB 1984, WSchofield, De Lorenzo, Johnstone, Mifflin, WHO/FAO, Owen, Fleisch, Wang and Rosenbaum) were determined at the time of diagnosis. Fat free mass (FFM) and fat mass (FM) were measured with impedancemetry. A Bland and Altman analysis was carried out. The percentage of accurate prediction $\pm 10 \%$ of $\mathrm{mREE}$, and intraclass correlation coefficients (ICC) were calculated. Using a derivation sample, a new REE formula was created using multiple linear regression according to sex, age, FFM and FM. Accuracy of this formula was assessed in a validation sample.

Results: ICC ranged between 0.60 and 0.71 (moderate agreement), and percentage of accurate prediction between $27.3 \%$ and $57.5 \%$. Underestimation was found from $31.7 \%$ to $71.4 \%$ of cases. According to these unsatisfactory results we created an ALS-specific formula in a derivation sample (130 patients). ICC and percentage of accurate prediction increased in a validation sample (143 patients) to 0.85 (very good agreement) and 65.0\% respectively, with $17.5 \%$ underestimation.

Conclusion: REE formulas for HP underestimate REE in ALS patients compared to mREE. Our new ALS-specific formula produced better results than formulas for HP. This formula can be used to estimate REE in ALS patients if IC is not accessible. 
47 Keywords: Amyotrophic lateral sclerosis, resting energy expenditure, predictive formula, 48 indirect calorimetry, new formula.

49

\section{Highlight:}

51 REE formulas predict REE with accuracy in less than $58 \%$ of cases in ALS.

52 REE formulas underestimate REE in 32 to $71 \%$ of cases in ALS.

53 ALS-specific formula improves percentage of accurate prediction of REE in ALS.

54 ALS-specific formula decreases underestimation of REE in ALS.

55 ALS-specific formula can be used if indirect calorimetry is not accessible. 


\section{Abbreviations}

58 ALS: amyotrophic lateral sclerosis

59 ALSFRS: amyotrophic lateral sclerosis functional rating scale

60 ALSFRS-R: amyotrophic lateral sclerosis functional rating scale-revised

61 BIA: bioelectric impedance analysis

62 BMI: body mass index

63 CI: confidence interval

64 WHO/FAO: world health organization / food and agriculture organization of the United 65 Nations.

66 FM: fat mass

67 FFM: free fat mass

68 HB: Harris and Benedict

69 IC: indirect calorimetry

70 IQR: interquartile range

71 Mifflin: Mifflin St. Jeor

72 PA: phase angle

73 cREE: calculated resting energy expenditure

74 mREE: measured resting energy expenditure

75 RQ: respiratory quotient

76 SD: standard deviation

77 TEE: total energy expenditure

78 TSF: triceps skin fold

79 WSchofield: World Schofield

80

81 


\section{Introduction}

Amyotrophic lateral sclerosis (ALS) is a rare neurodegenerative disease affecting motor neurons, age at diagnosis is 65-70 years (1-4) and its incidence is stable at around 2/ 100000 person years in Western populations (5). The prognosis is severe, with a median survival in Europe of 25 to 30 months from onset (4).

ALS patients are at risk of malnutrition in the short and medium term (9-55\% according to the literature) $(1,6,7)$. Causes may include increased resting energy expenditure (REE) (7-12) which if not compensated by diet, may cause weight loss. REE may be measured (mREE) with indirect calorimetry (IC) $(9,10,13-16)$,but because of the low availability of this highcost apparatus, and the length of time necessary for each measurement ( $\geq 20 \mathrm{~min}$ ), predictive formulas have been developed to provide calculated REE (cREE). The most widely used is Harris and Benedict 1919 (HB1919) $(9,10,13,14,16)$. The Mifflin St. Jeor (Mifflin) formula is also used $(17,18)$. The difference between mREE and cREE allows for the definition of energy metabolism disorder. A difference between mREE and cREE of more than $10 \%$ defines hypermetabolism, which is found in 50-60\% of ALS patients (7-10,19). REE may increase from +10 to $+20 \%$ in these patients. For Sherman et al., HB 1919 is not valid when used to predict REE in ALS patients (16). Kasarskis et al. and Shimizu et al. recently created total energy expenditure (TEE) formulas for ALS patients using HB1919 and Mifflin formulas for REE prediction. These REE formulas were constructed for healthy people (20). Currently, no REE formulas are validated for ALS patients.

The objectives here were, in ALS patients: (i) to assess the accuracy of cREE calculated with 11 predictive formulas, commonly used in healthy patients (HB 1919, HB 1984, World Schofield (WSchofield), De Lorenzo, Johnstone, Mifflin) (20) and used in ALS studies (HB 1919, world health organization / food and agriculture organization of the United Nations (WHO/FAO), Owen, Fleisch, Wang, Rosenbaum, Mifflin) $(9,10,17,21)$ as compared to 
107 mREE assessed using IC, and; (ii) to create, if necessary a REE formula adapted to ALS

108 patients and suitable for use in clinical practice without IC.

109 
111 ALS patients followed in the ALS expert center in Limoges (France) from November 1996 to

112 November 2014 with nutritional, neurological and respiratory assessments were included. The

113 assessments were performed after diagnosis and then regularly until the patient died.

114 Nutritional assessment included the use of indirect calorimetry to measure REE.

116 Inclusion criteria:

117 We included patients with ALS diagnosed according to Airlie House criteria (definite,

118 probable, or laboratory-supported probable and possible) (22) and treated with riluzole.

119 Patients could also have had ALS associated with frontotemporal dementia. The respiratory

120 quotient (RQ) of patients by indirect calorimetry (IC) was required to be between 0.7 and

1210.87 (23). IC and the other nutritional assessments had to have been performed within 1.5

122 months, and IC had to be performed no more than 12 months after diagnosis.

124 Data collection:

125 The data were extracted prospectively from the CleanWEB ${ }^{\mathrm{TM}}$ database of the ALS expert 126 center, which has been validated by the Commission Nationale de l'Informatique et des 127 Libertés (CNIL; No. 1244525). Patients gave given informed consent for data collection. The 128 ClinicalTrial registration number is NCT03378375.

130 Nutritional assessments:

131 General data collected were: sex, date of diagnosis, date of calorimetry.

132 Nutritional assessment was carried out in the nutrition unit after diagnosis in the Nutrition

133 Unit. Patients were weighed (to $0.1 \mathrm{~kg}$ ) in underwear using a SECA ${ }^{\circledR}$ electronic balance 134 (Vogel \& Halke, Hamburg, Germany) in an upright position or on a SECA ${ }^{\circledR}$ weighing chair if 
135 they could not stand upright. Usual weight 6 months before onset of symptoms was collected

136 allowing the calculation of the percentage of initial weight loss relative to the usual weight.

137 Their height (in $\mathrm{m}$ ) was measured using a $\mathrm{SECA}^{\circledR}$ gauge recording to $0.2 \mathrm{~cm}$ (Vogel \& Halke,

138 Hamburg, Germany) in an upright position or using the Chumlea formulas for people over 60

139 years who could not be verticalized (24). BMI (in $\mathrm{kg} / \mathrm{m}^{2}$ ) was calculated using the formula:

140 BMI $\left(\mathrm{kg} / \mathrm{m}^{2}\right)=$ weight $(\mathrm{kg}) /$ height $*$ height $\left(\mathrm{m}^{2}\right)$. The triceps skinfold (TSF) was obtained

141 from the average of three measurements on each side with a Harpenden caliper (Baty

142 International, Burgess Hill, UK) according to the usual modalities (25). Fat free mass (FFM in

$143 \mathrm{~kg}$ ) and fat mass (FM in $\mathrm{kg}$ ) were calculated with the validated formula for ALS patients

144 using weight, TSF and total body impedance at $50 \mathrm{kHz}$ in bioelectric impedance analysis

145 (BIA) Analycor ${ }^{\circledR}$ (Eugédia, Chambly, France) in supine position after 5 min of rest (26). The

146 impedancemetry also allowed for measurement of the phase angle (PA) marker of cellular

147 function (27). Measured REE (mREE in kcal / 24h) by IC was obtained with the Quark

$148 \mathrm{RMR}^{\circledR}$ with canopy (Cosmed, Rome, Italy) after a calibration of the instrument $( \pm 0.02 \%$ on

149 measures of expired volumes of CO2 and inspired volumes of O2) (23). It was performed in

150 the morning after 12 hours of fasting, in a supine position and at rest. The patient was not

151 physically active before the IC, and did not sleep during the exam or hyperventilate. The

152 cREE was calculated (cREE in kcal / 24h) according to eleven predictive formulas (HB 1919,

153 HB 1984, WSchofield, De Lorenzo, Johnstone, Mifflin, WHO/FAO, Owen, Fleisch, Wang

154 and Rosenbaum) (Table 1). Formulas with results in kj (WSchofield, De Lorenzo and

155 Johnstone) were converted into kcal by multiplying by 0.2388 . The REE variation (bias in \%)

156 was calculated according to the formula: cREE ( $\mathrm{kcal} / 24 \mathrm{~h})-\mathrm{mREE}(\mathrm{kcal} / 24 \mathrm{~h}) / \mathrm{mREE}(\mathrm{kcal}$

$157 / 24 \mathrm{~h}) * 100$. The thresholds of accurate prediction of cREE compared to mREE is of $\pm 10 \%$.

158 Overestimation was $>10 \%$ of measured value and underestimation was $<10 \%$ of measured

159 value (20). 
161 Statistical analysis:

162 Statistical analysis was performed using SAS $^{\circledR}$ software v9.3 (SAS Institute, Cary, North

163 Carolina, USA) and GraphPad Prism 6.0 (GraphPad Software Inc, La Jolla, CA, USA). The

164 threshold of significance for all statistical analyses was $p<0.05$. We complied with the

165 STROBE statement (28). Quantitative variables were expressed with the median (interquartile

166 range $[\mathrm{IQR}]$ ) or mean \pm standard deviation (SD). Qualitative variables were expressed in

167 frequency and percentage. Normality of quantitative variables was studied using the Shapiro-

168 Wilk test. Quantitative variables were compared using non-parametric Mann-Whitney test,

169 and qualitative variables were compared using Chi2.

170

171 Agreement between mREE and cREE

172 The REE variation (bias in \%) was calculated according to the formula: cREE (kcal / 24h) -

$173 \mathrm{mREE}(\mathrm{kcal} / 24 \mathrm{~h}) / \mathrm{mREE}(\mathrm{kcal} / 24 \mathrm{~h}) * 100$. The threshold of accurate prediction of $\mathrm{cREE}$

174 compared to mREE was $\pm 10 \%$. Overestimation is $>10 \%$ of measured value and

175 underestimation is $<10 \%$ of measured value (29). The percentage of prediction between the

$17695 \%$ limit of agreement $( \pm 2 \mathrm{SD})$ and the error risk were computed. The mean percentage

177 difference between cREE and mREE (bias in kcal / 24h and \%) was calculated.

178

$179 \quad$ Formula derivation and validation

180 The entire sample was split at random into a derivation and a validation subsample. The

181 construction of the formula for REE in ALS patients was based on the following steps using

182 the derivation sample : (i) detection and elimination of outliers, decision based on the Cook's

183 D influence statistics (threshold 4/n); (ii) simple linear regression analysis considering mREE

184 as the dependent variable and the following independent variables : age, sex, height, weight, 
185 FM, FFM and PA assessed using BIA; (iii) multiple linear regression analysis considering as

186 independent variables those with a p-value $<0.20$ in the simple regression, the first model was

187 simplified step by step, confounders were checked at each step; (iv) check of the linear nature

188 of the relation between dependent and independent variables; (v) evaluation of the normality

189 (using Shapiro-Wilk test and Kernel and qq plot graphs) and homoscedastisticy (White test =

190 0.42) of the residuals of the final model; (vi) check for any misspecification of the final model

191 (vii) check for multicollinearity among independent variables included in the final model,

192 (viii) check for interaction between independent variables.

193 Based on the coefficient of the multiple linear regression, REE was estimated in the validation

194 sample. Assessment of the agreement between mREE and REE estimated by our equation was

195 based on the above mentioned strategy.

196

197 
199 Study sample

200 From November 1996 to November 2014, 405 ALS patients had IC. Ninety patients were 201 excluded: 35 for a RQ $<0.7$ or $>0.87 ; 30$ because the time lag between IC and nutritional 202 assessment was over 1.5 months; and 25 because the delay between diagnosis and IC was 203 over 12 months. The flowchart of patients included and not included is shown in Figure 1.

204 The 315 included patients had a median age at diagnosis of 65.9 years $(56.5-73.7)$, with a 205 sex ratio of 1.0. The median delay between diagnosis and nutritional assessment was 4.3 months $(2.2$ - 6.6). The median mREE with IC was of $1503 \mathrm{kcal} / 24 \mathrm{~h}(1290-1698)$. The nutritional, and neurological characteristics of the patients included are presented in Table 2.

$\underline{\text { cREE accuracy }}$

The results of cREE prediction with the 11 REE formulas in the entire sample $(n=315)$ are presented in Table 3. The analysis found moderate agreement between mREE and cREE, with an ICC range between $0.60(-0.07-0.84)$ and $0.71(0.54-0.81)$.

213 Figure 2 shows the Bland and Altman plots for the 11 formulas. With a threshold of $\pm 10 \%$

214 difference between mREE and cREE, the proportion of accurate prediction ranged between $27.3 \%$ and $57.5 \%$. An underestimation of REE (REE variation < 10\%) was found in $31.7 \%$ to $71.4 \%$ of cases.

\section{$\underline{\text { ALS-specific REE formula derivation and validation }}$}

218 Given these results (high percentage of underestimation of REE formula in ALS patients) we 219 attempted to create a new formula. Some patients were excluded from the derivation and 220 validation subsamples due to lack of BIA measurement and others were excluded from the 221 derivation because they had been detected as outliers (hence their inclusion was not 222 desirable). Both subsamples displayed a high level of comparability only with BMI, which 
223 was slightly higher in the derivation sample compared to the validation sample: $24.8 \mathrm{~kg} / \mathrm{m}^{2}$ $224(22.3-27.7)$ vs. $23.6 \mathrm{~kg} / \mathrm{m}^{2}(21.8-26.5)$, respectively $(\mathrm{p}=0.047)$ (Table 2$)$.

225 After the simple linear regression analysis, age, sex, height, weight, FM, FFM and PA 226 assessed using BIA were considered to enter the first multiple linear regression model (p227 values $<0.0001$ for all these variables, except for FM: $\mathrm{p}=0.0014$ ). After a step by step 228 simplification of the model, age, sex, FM and FFM were retained in the final model (p-values $229<0.0001$ for all these variables, except for age: $p=0.004)$. The graphical evaluation of the 230 linear nature of the relation between the dependent and the independent variables was 231 satisfactory. The residuals of the model were considered as normally distributed (Shapiro 232 Wilk test $\mathrm{p}=0.58$, satisfactory Kernel and qq plot graphs) and with a constant error variance 233 (White test $\mathrm{p}=0.42$ ). The model was shown to be correctly specified, there was no 234 multicollinearity or interaction between dependent variables.

236 The formula based on the coefficient of the model from the derivation sample (130 patients) 237 appeared as follows:

$238 \mathrm{cREE}(\mathrm{kcal} / 24 \mathrm{~h})=901.34-(5.82 *$ age $[$ years $])+(15.65 * \mathrm{FFM}[\mathrm{kg}])+(8.88 * \mathrm{FM}[\mathrm{kg}])$ $239+145.21$ if men. The R-square of the model was $76 \%$.

241 In the validation sample, our formula was compared to the 11 other REE formulas (Table 4) 242 and to mREE; results were the same as for the entire sample. The ICC between mREE and 243 REE estimated using our formula was $0.85(0.79-0.89)$ (i.e. very good agreement) (Table 3). 244 Figure 3 shows the Bland and Altman plots for the 11 formulas and our new formula in the 245 validation sample. With the threshold of $\pm 10 \%$ of mREE, the percentage of accurate 246 prediction was $65 \%$ (-347.7 to $304.4 \mathrm{kcal} / 24 \mathrm{~h})$ with only $17.5 \%$ underestimation. Accurate 247 prediction was significantly higher with our formula than eight of the other 11 
248 formulas used, $45.5 \%, 49.7 \%, 49.0 \%, 51.7 \%, 34.3 \%, 26.6 \%, 30.1 \%$ and $43.4 \%$ for HB 1919 , 249 HB 1984, WSchofield, De Lorenzo, Johnstone, Mifflin, Wang and Rosenbaum, respectively $250(\mathrm{p}=0.0009, \mathrm{p}=0.0085, \mathrm{p}=0.006, \mathrm{p}=0.023, \mathrm{p}<0.0001, \mathrm{p}<0.0001, \mathrm{p}<0.0001$ and $\mathrm{p}=$ 2510.0002 respectively). However, though lower than our formulas, accurate prediction was not 252 significantly different with WHO/FAO, Owen and Fleisch $(55.2 \%, \mathrm{p}=0.09,56.6 \%, \mathrm{p}=0.15$ 253 and $55.9 \%, p=0.12$, respectively). Underestimation was significantly lower with our formula $254(17.5 \%)$ than the 11 formulas used $51.0 \%, 46.2 \%, 45.5 \%, 44.8 \%, 62.9 \%, 71.3 \%, 34.3 \%$, $25533.6 \%, 39.9 \%, 66.6 \%$, and $50.3 \%$ for $\mathrm{HB}$ 1919, HB 1984, WSchofield, De Lorenzo, 256 Johnstone, Mifflin, WHO/FAO, Owen, Fleisch, Wang and Rosenbaum, respectively ( $<$ 257 0.0001, $\mathrm{p}<0.0001, \mathrm{p}<0.0001, \mathrm{p}<0.0001, \mathrm{p}<0.0001, \mathrm{p}<0.0001, \mathrm{p}=0.001, \mathrm{p}=0.002, \mathrm{p}<$ $2580.0001, \mathrm{p}<0.0001$ and $\mathrm{p}<0.0001$, respectively). 
261 This study is the first to consider the accuracy of 11 REE formulas in a large sample of ALS 262 patients $(n=315)$, with the creation of an ALS-specific REE formula which was validated in 263 an independent subsample.

264 Assessment of the level of REE in ALS patients is important as it helps to better match the 265 diet to the metabolic disorders present in ALS. This allows to better adapt energy intake in 266 case of hypermetabolism, which is found in 50-60\% during this disease according to HB 1919 to predict cREE $(9,10)$. If this adjustment is not made, patients are exposed to weight loss and accelerated development of undernutrition, which is an important risk factor for death in ALS $(1,3,6)$. In addition, better food intake could allow increased FM, which is a positively associated with survival (1). The reference measurement method for REE, indirect 271 calorimetry, is often unavailable in clinical practice due to lack of equipment. Even if it is possible, it is still time consuming. For these reasons, reliable predictive formulas are important. HB 1919 formulas are frequently used to assess energy need in various diseases including ALS (9,10,16,17,21,30-33). Sherman et al. alone performed, in 2004, a Bland and Altman analysis to compare HB 1919 formulas with mREE in IC in a small sample of 34 ALS patients with and without ventilation (16). HB 1919 are not adapted to predict REE of ALS patient. Other studies published focused on mREE and cREE are presented in Table 5. In our study we found a mREE in IC of $1514 \pm 283 \mathrm{kcal} / 24 \mathrm{~h}$ in agreement with the literature $(9,10,15,17)$. Sherman et al. reported slightly lower results in 16 non-ventilated patients $(16)$.

280 This discrepancy may be due to differences in the IC apparatus used. Our study shows that, in 281 a large population of ALS patients, the 11 predictive formulas used are not adapted to ALS 282 patients. The main problem with these formulas is underestimation of the energy requirement in $31.7 \%$ to $71.4 \%$ of patients, with a real risk of inadequate energy intake, which can lead to 284 weight loss and undernutrition. Reasons for this maladjustment are probably diverse. The 
main issue is the absence of validation of these REE formulas in ALS patients with alteration 286 of the body composition. Indeed, ALS, patients lose FFM and increase their FM $(1,9,10)$. In 287 addition, the numbers of ALS patients to whom these equations were applied were sometimes 288 low, and patient characteristics may be very different $(13,15,16)$. Given these difficulties, we created a new formula that allows for better prediction and less underestimation of REE in ALS patients. This formula integrates body composition data (FFM and FM) obtained with impedancemetry according to a validated method which is easy, fast and noninvasive for ALS patients (26). Moreover, body composition is a better reflection of nutritional status than weight and height used in several REE predictive formula. REE is therefore related to FFM. The recent ESPEN guidelines for ALS, propose to use HB 1919 equations to assess energy needs in the absence of IC (34). But because of the poor agreement of HB 1919 formulas in ALS, an ALS-specific formula seems necessary. In absence of IC, this new formula could be used easily in clinical practice to diagnose hypermetabolism at onset of the disease and to adapt energy needs in ALS during follow up.

However, there are several limitations to our study. Although the ALS referral center follows $88.2 \%$ of ALS patients in our region, this population is not totally representative of patients 301 in the region and country (2). There is therefore a selection bias. Moreover, it would be 302 desirable to validate the new formula in a sample of ALS patients from another center and in 303 a population-based setting if possible. This new formula found a poor REE prediction for $30435 \%$ of patients, suggesting that other elements determining REE of ALS patients were not 305 taken into account $\left(\mathrm{R}^{2}\right.$ of the model was $\left.76 \%\right)$. These remain to be discovered (35), as it is 306 known that neither the intensity of the fasciculations, smoking, nor any inflammatory or 307 infectious condition is implicated $(9,10,35)$. Cortical hyperexcitability could be related to 308 metabolic dysfunction in ALS and could increase glucose metabolism in the brains of ALS 309 patients $(36,37)$. However, there is currently no recognised link between REE in indirect 
310 calorimetry and brain hypermetabolism. It is therefore difficult to integrate this parameter into

311 a REE predictive formula used in daily practice. We did not calculate the sample size a priori

312 but verified that the power was sufficient given the size of the study. For example, the linear

313 regression used for formula derivation was at least of $80 \%$ even considering an independent

314 variable that would be weakly correlated to the dependent variable ( $r=0.25$, e.g.). 
317 When REE formulas for healthy people are used in ALS patients, they provide an accurate 318 prediction of REE ( $\pm 10 \%$ of $\mathrm{mREE}$ ) in less than $58 \%$ of cases, with a high level of 319 underestimation up to $71 \%$ of cases. These formulas are not adapted to predict REE in ALS 320 patients, and their use can lead to underestimation of energy need with weight loss and 321 malnutrition, which are important prognosis factors in ALS. The creation of an ALS-specific 322 REE formula using body composition allows prediction of REE in $65 \%$ of cases with only $32317.5 \%$ underestimation. Agreement between mREE and estimated REE using the formula was 324 very good $(0.85)$. This formula can therefore be used to predict REE in clinical practice in 325 ALS patients if indirect calorimetry is not available. Validation in another independent 326 sample of ALS patients is required. 
328 Acknowledgements: We thank the Mr Francis William for the translation of the manuscript.

330 Authors' contributions:

331 PJ, PC, JCD and BM designed the research; PJ, PF, HS, GL, PC and JCD conducted the 332 research; PJ, PF, MN, GL, PC and JCD provided essential materials (databases); PJ and BM

333 performed statistical analysis; PJ, PF, PMP, PC, JCD, BM wrote the paper; PJ and BM had 334 primary responsibility for the final content. All authors read and approved the final 335 manuscript.

336

337 Conflict of Interest (COI) Statement: Authors had no financial or personal relationships 338 with companies or organizations sponsoring the research at the time it was carried out.

340 Source of support: none 


\section{References}

343 1. Marin B, Desport JC, Kajeu P, Jesus P, Nicolaud B, Nicol M, et al. Alteration of 344 nutritional status at diagnosis is a prognostic factor for survival of amyotrophic lateral 345 sclerosis patients. J Neurol Neurosurg Psychiatry. 2011;82(6):628-34.

346 2. Marin B, Hamidou B, Couratier P, Nicol M, Delzor A, Raymondeau M, et al. 347 Population-based epidemiology of amyotrophic lateral sclerosis (ALS) in an ageing 348 Europe - the French register of ALS in Limousin (FRALim register). Eur J Neurol. 2014;21(10):1292-e79.

3. Marin B, Arcuti S, Jesus P, Logroscino G, Copetti M, Fontana A, et al. PopulationBased Evidence that Survival in Amyotrophic Lateral Sclerosis Is Related to Weight Loss at Diagnosis. Neurodegenerative Diseases. 2016;16(3-4):225-34.

4. Marin B, Logroscino G, Boumédiene F, Labrunie A, Couratier P, Babron M-C, et al. Clinical and demographic factors and outcome of amyotrophic lateral sclerosis in relation to population ancestral origin. Eur J Epidemiol. 2016;31(3):229-45.

5. Marin B, Boumédiene F, Logroscino G, Couratier P, Babron M-C, Leutenegger AL, et al. Variation in worldwide incidence of amyotrophic lateral sclerosis: a meta-analysis. Int J Epidemiol 2017;46(1):57-74.

6. Desport JC, Preux PM, Truong TC, Vallat JM, Sautereau D, Couratier P. Nutritional status is a prognostic factor for survival in ALS patients. Neurology. 1999;53(5):1059-

7. Genton L, Viatte V, Janssens J-P, Héritier A-C, Pichard C. Nutritional state, energy intakes and energy expenditure of amyotrophic lateral sclerosis (ALS) patients. Clinical Nutrition. 2011;30(5):553-9. 
365 8. Muscaritoli M, Kushta I, Molfino A, Inghilleri M, Sabatelli M, Rossi Fanelli F. 366 Nutritional and metabolic support in patients with amyotrophic lateral sclerosis. $367 \quad$ Nutrition. 2012;28(10):959-66.

368 9. Desport J-C, Torny F, Lacoste M, Preux P-M, Couratier P. Hypermetabolism in ALS: 369 Correlations with Clinical and Paraclinical Parameters. Neurodegenerative Diseases. 2005;2(3-4):202-7.

10. Bouteloup C, Desport J-C, Clavelou P, Guy N, Derumeaux-Burel H, Ferrier A, et al. Hypermetabolism in ALS patients: an early and persistent phenomenon. J Neurol. 2009;256(8):1236-42.

11. Marin B, Jésus P, Preux P-M, Couratier P, Desport JC. Troubles nutritionnels lors de la sclérose latérale amyotrophique (SLA). Nutr Clin Metab. 2011;25:205-216.

12. Ngo ST, Steyn FJ, McCombe PA. Body mass index and dietary intervention: implications for prognosis of amyotrophic lateral sclerosis. J Neurol Sci. 2014;340(1-

13. Funalot B, Desport J-C, Sturtz F, Camu W, Couratier P. High metabolic level in patients with familial amyotrophic lateral sclerosis. Amyotroph Lateral Scler. 2009;10(2):113-7.

14. Kasarskis EJ, Berryman S, Vanderleest JG, Schneider AR, McClain CJ. Nutritional 382 status of patients with amyotrophic lateral sclerosis: relation to the proximity of death. Am J Clin Nutr. 1996;63(1):130-7.

15. Vaisman N, Lusaus M, Nefussy B, Niv E, Comaneshter D, Hallack R, et al. Do patients with amyotrophic lateral sclerosis (ALS) have increased energy needs? Journal of the Neurological Sciences. 2009;279(1-2):26-9. 
16. Sherman MS, Pillai A, Jackson A, Heiman-Patterson T. Standard Equations Are Not Accurate in Assessing Resting Energy Expenditure in Patients With Amyotrophic Lateral Sclerosis. JPEN J Parenter Enteral Nutr. 2004;28(6):442-6.

17. Kasarskis EJ, Mendiondo MS, Matthews DE, Mitsumoto H, Tandan R, Simmons Z, et al. Estimating daily energy expenditure in individuals with amyotrophic lateral sclerosis. Am J Clin Nutr. 2014;99(4):792-803.

18. Lee J, Baek H, Kim SH, Park Y. Association between estimated total daily energy expenditure and stage of amyotrophic lateral sclerosis. Nutrition. 2017;33:181-6.

19. Haute Autorité de Santé (HAS). Prise en charge des personnes atteintes de SLA- Texte des recommandations version longue. Rev Neurol. 2006;162(HS 2):4S363.

20. Jésus P, Achamrah N, Grigioni S, Charles J, Rimbert A, Folope V, et al. Validity of predictive equations for resting energy expenditure according to the body mass index in a population of 1726 patients followed in a Nutrition Unit. Clinical Nutrition. 2015;34(3):529-35.

21. Siirala W, Olkkola KT, Noponen T, Vuori A, Aantaa R. Predictive equations overestimate the resting energy expenditure in amyotrophic lateral sclerosis patients who are dependent on invasive ventilation support. Nutr Metab (Lond). 2010;7:70.

22. Brooks BR, Miller RG, Swash M, Munsat TL, World Federation of Neurology Research Group on Motor Neuron Diseases. El Escorial revisited: revised criteria for the diagnosis of amyotrophic lateral sclerosis. Amyotroph Lateral Scler Other Motor Neuron Disord. 2000;1(5):293-9. 
23. Ferrannini E. The theoretical bases of indirect calorimetry: A review. Metabolism. 1988;37(3):287-301.

24. Chumlea WC, Roche AF, Steinbaugh ML. Estimating stature from knee height for persons 60 to 90 years of age. J Am Geriatr Soc. 1985;33(2):116-20.

25. Frisancho AR. New norms of upper limb fat and muscle areas for assessment of nutritional status. Am J Clin Nutr. 1981;34(11):2540-5.

26. Desport JC, Preux PM, Bouteloup-Demange C, Clavelou P, Beaufrère B, Bonnet C, et al. Validation of bioelectrical impedance analysis in patients with amyotrophic lateral sclerosis. Am J Clin Nutr. 2003;77(5):1179-85.

27. Desport J-C, Marin B, Funalot B, Preux P-M, Couratier P. Phase angle is a prognostic factor for survival in amyotrophic lateral sclerosis. Amyotroph Lateral Scler. 2008;9(5):273-8.

28. Cohen JF, Korevaar DA, Altman DG, Bruns DE, Gatsonis CA, Hooft L, et al. STARD 2015 guidelines for reporting diagnostic accuracy studies: explanation and elaboration. BMJ Open. 2016;6(11):e012799.

29. Bland JM, Altman DG. Comparing methods of measurement: why plotting difference against standard method is misleading. The Lancet. 1995;346(8982):1085-7.

30. Shimizu T, Ishikawa-Takata K, Sakata A, Nagaoka U, Ichihara N, Ishida C, et al. The measurement and estimation of total energy expenditure in Japanese patients with ALS: a doubly labelled water method study. Amyotrophic Lateral Sclerosis and Frontotemporal Degeneration. 2017;18(1-2):37-45. 
31. Takemura Y, Sasaki M, Goto K, Takaoka A, Ohi A, Kurihara M, et al. Energy metabolism and nutritional status in hospitalized patients with lung cancer. Journal of Clinical Biochemistry and Nutrition. 2016;59(2):122.

32. Oliveira B, Sridharan S, Farrington K, Davenport A. Comparison of resting energy equations and total energy expenditure in haemodialysis patients and body composition measured by multi-frequency bioimpedance. Nephrology (Carlton). 2017.

33. Kruizenga HM, Hofsteenge GH, Weijs PJM. Predicting resting energy expenditure in underweight, normal weight, overweight, and obese adult hospital patients. Nutrition \& Metabolism. 2016;13(1):85.

34. Burgos R, Bretón I, Cereda E, Desport JC, Dziewas R, Genton L, et al. ESPEN guideline clinical nutrition in neurology. Clin Nutr. 2018;37(1):354-396.

35. Ioannides ZA, Steyn FJ, Henderson RD, Mccombe PA, Ngo ST. Anthropometric measures are not accurate predictors of fat mass in ALS. Amyotrophic Lateral Sclerosis and Frontotemporal Degeneration. 2017;0(0):1-6.

36. Cistaro A, Valentini MC, Chiò A, Nobili F, Calvo A, Moglia C, et al. Brain hypermetabolism in amyotrophic lateral sclerosis: a FDG PET study in ALS of spinal and bulbar onset. Eur J Nucl Med Mol Imaging. 2011;39(2):251-9.

37. Buhour M-S, Doidy F, Mondou A, Pélerin A, Carluer L, Eustache F, et al. Voxel-based mapping of grey matter volume and glucose metabolism profiles in amyotrophic lateral sclerosis. EJNMMI Research. 2017;7:21.

38. Harris JA, Benedict FG. A Biometric Study of Human Basal Metabolism. Proc Natl Acad Sci U S A. 1918 Dec;4(12):370-3. 
451 39. Roza AM, Shizgal HM. The Harris Benedict equation reevaluated: resting energy 452 requirements and the body cell mass. Am J Clin Nutr. 1984;40(1):168-82.

453 40. Johnstone AM, Rance KA, Murison SD, Duncan JS, Speakman JR. Additional 454 anthropometric measures may improve the predictability of basal metabolic rate in adult $455 \quad$ subjects. Eur J Clin Nutr. 2006;60(12):1437-44.

456 41. Mifflin MD, St Jeor ST, Hill LA, Scott BJ, Daugherty SA, Koh YO. A new predictive 457 equation for resting energy expenditure in healthy individuals. Am J Clin Nutr. $458 \quad 1990 ; 51(2): 241-7$.

459

460 


\section{Figure Legends:}

462 Figure 1: Flowchart of patients with ALS included in the study.

463 ALS: amyotrophic lateral sclerosis; BIA: body impedance analysis; n: number; RQ: 464 respiratory quotient; REE: resting energy expenditure.

466 Figure 2: Bland and Altman graphics between calculated resting energy expenditure with the 46711 formulas and measured resting energy expenditure in the entire sample $(n=315)$. Panel A: 468 Harris and Benedict 1919, panel B: Harris and Benedict 1984, panel C: World Schofield, 469 panel D: De Lorenzo, panel E: Johnstone, panel F: Mifflin St. Jeor, panel G: WHO/FAO 470 (world health organization / food and agriculture organization of the United Nations), panel 471 H: Owen, panel I: Fleisch, panel J: Wang and panel K: Rosenbaum.

472 REE: resting energy expenditure; SD: standard deviation

474 Figure 3: Bland and Altman graphics between calculated resting energy expenditure with the 47511 formulas and the constructed formula and measured resting energy expenditure in the 476 validation sample ( $\mathrm{n}=143)$. Panel A: Harris and Benedict 1919, panel B: Harris and Benedict 477 1984, panel C: World Schofield, panel D: De Lorenzo, panel E: Johnstone, panel F: Mifflin 478 St. Jeor, panel G: WHO/FAO (world health organization / food and agriculture organization 479 of the United Nations), panel H: Owen, panel I: Fleisch, panel J: Wang, panel K: Rosenbaum 480 and panel L: constructed formula.

481 REE: resting energy expenditure; SD: standard deviation 


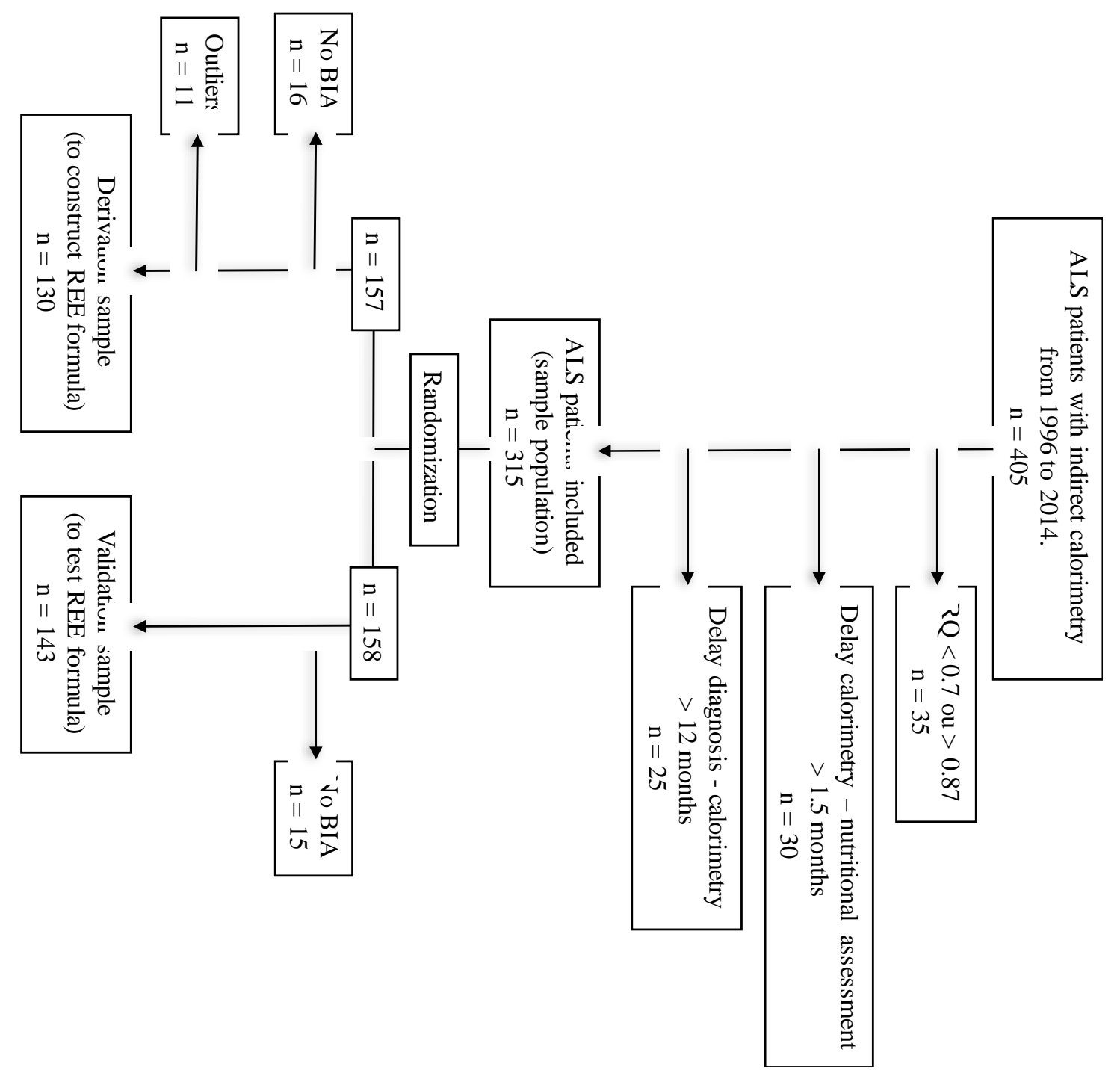

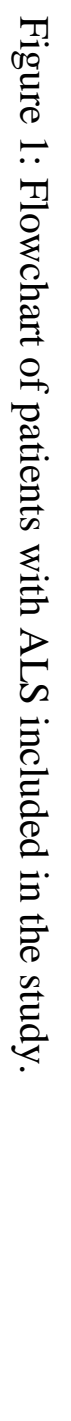


Figure 3: Bland and Altman graphics between calculated resting energy expenditure with the 11 formulas and the constructed formula and measured resting energy expenditure in the validation sample $(n=143)$.
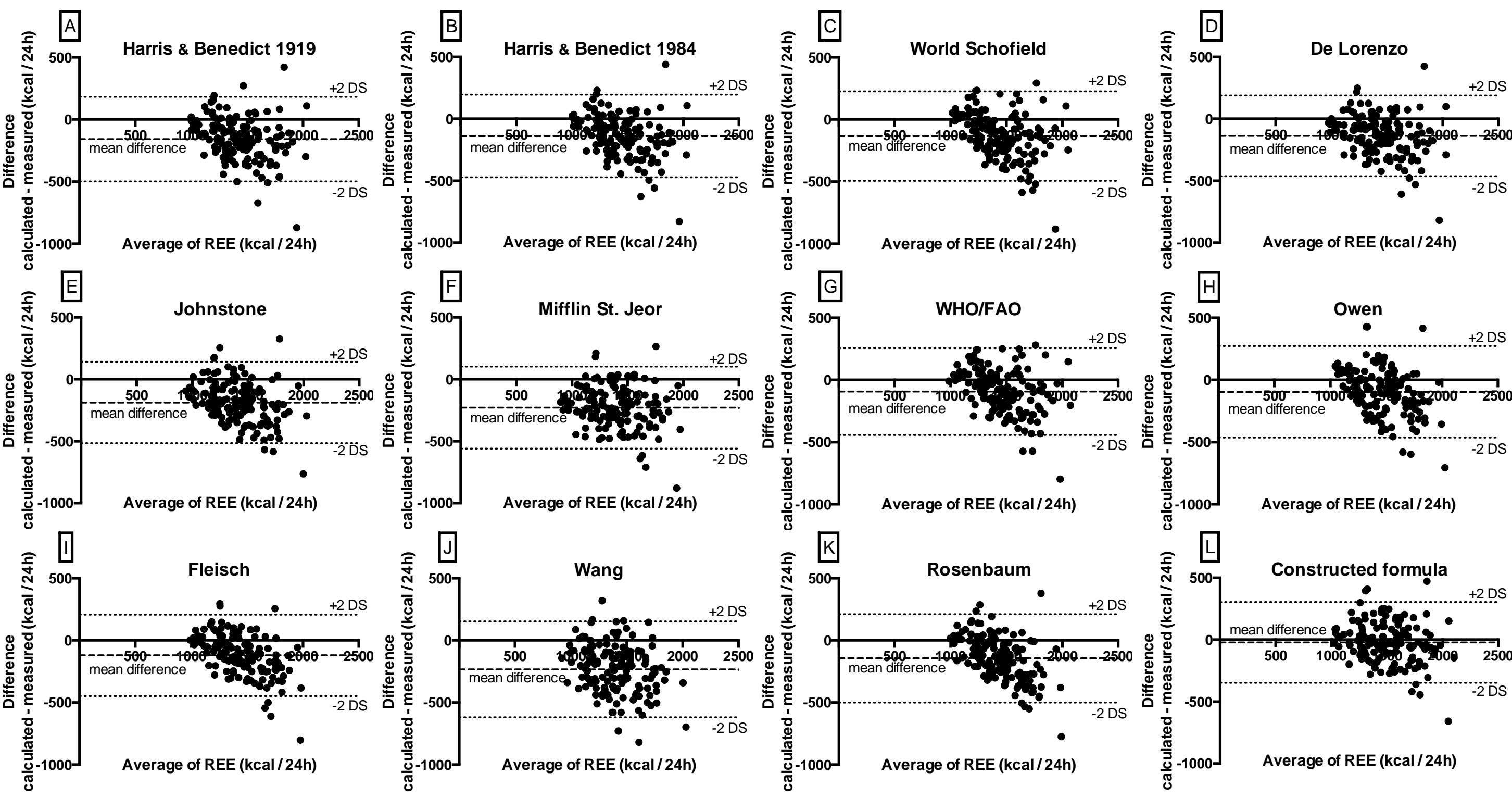
Table 1: Resting energy expenditure formulas tested and new formula constructed.

\begin{tabular}{|c|c|}
\hline Harris \& Benedict $1919(38)$ & $\begin{array}{l}\text { - Male: }(\text { Weight }(\mathrm{kg}) * 13.7516)+(\text { Height }(\mathrm{cm}) * 5.0033)-(\text { Age }(\text { years }) * 6.755)+66.473 \\
\text { - Female: }(\text { Weight }(\mathrm{kg}) * 9.5634)+(\text { Height }(\mathrm{cm}) * 1.8496)-(\text { Age }(\text { years }) * 4.6756)+655.0955\end{array}$ \\
\hline Harris \& Benedict 1984 (39) & $\begin{array}{l}\text { - Male: }(\text { Weight }(\mathrm{kg}) * 13.397)+(\text { Height }(\mathrm{cm}) * 4.799)-(\text { Age }(\text { years }) * 5.677)+88.362 \\
\text { - Female: }(\text { Weight }(\mathrm{kg}) * 9.247)+(\text { Height }(\mathrm{cm}) * 3.098)-(\text { Age }(\text { years }) * 4.33)+477.593\end{array}$ \\
\hline World Schofield(20) & $\begin{array}{l}\text { - Male of } 18 \text { - } 30 \text { years: }(0.063 * \text { Weight }(\mathrm{kg}))+2.896 \\
\text { - Male of } 30 \text { - } 60 \text { years: }(0.048 * \text { Weight }(\mathrm{kg}))+3.653 \\
\text { - Male > } 60 \text { years: }(0.049 * \text { Weight }(\mathrm{kg}))+2.459 \\
\text { - Female of } 18 \text { - } 30 \text { years: }(0.062 * \text { Weight }(\mathrm{kg}))+2.036 \\
\text { - Female of } 30 \text { - } 60 \text { years: }(0.034 * \text { Weight }(\mathrm{kg}))+3.538 \\
\text { - Female > } 60 \text { years: }(0.038 * \text { Weight }(\mathrm{kg}))+2.755\end{array}$ \\
\hline De Lorenzo(20) & $\begin{array}{l}\text { - Male: }(53.284 * \text { Weight }(\mathrm{kg}))+(20.957 * \text { Height }(\mathrm{cm}))-(23.859 * \text { Age }(\text { years }))+487 \\
\text { - Female: }(46.322 * \text { Weight }(\mathrm{kg}))+(15.744 * \text { Height }(\mathrm{cm}))-(16.66 * \text { Age }(\text { years }))+944\end{array}$ \\
\hline Johnstone (40) & $(90.2 * \mathrm{FFM}(\mathrm{kg}))+(31.6 * \mathrm{FM}(\mathrm{kg}))-(12.2 *$ Age $($ years $))+1613$ \\
\hline Mifflin St. Jeor (41) & $\begin{array}{l}\text { - Male: }(9.99 * \text { Weight }(\mathrm{kg}))+(6.2 * \text { Height }(\mathrm{cm}))-(4.92 * \text { Age }(\text { years }))+5 \\
\text { - Female: }(9.99 * \text { Weight }(\mathrm{kg}))+(6.2 * \text { Height }(\mathrm{cm}))-(4.92 * \text { Age }(\text { years }))-161\end{array}$ \\
\hline
\end{tabular}




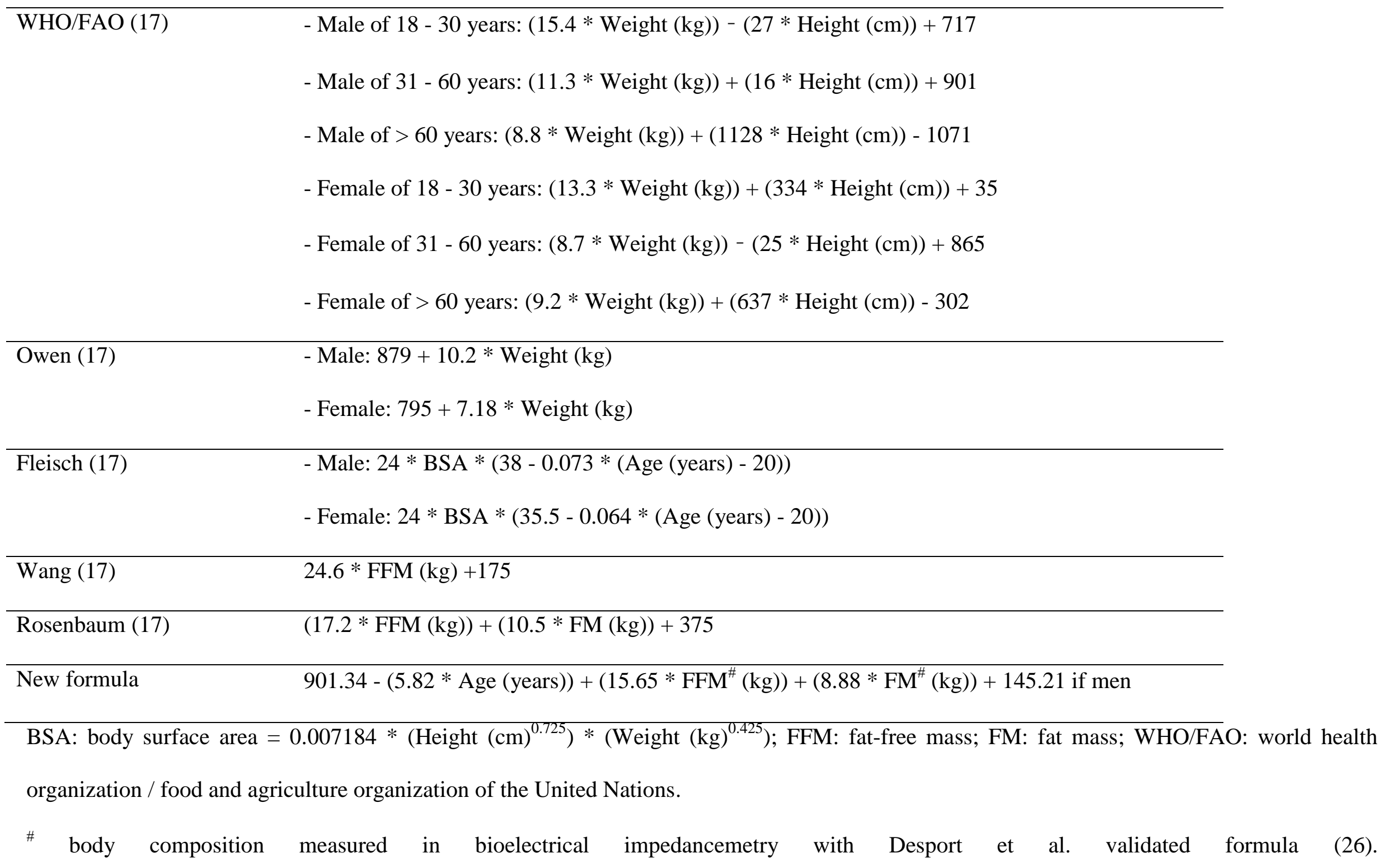


Table 2: Nutritional characteristics of included patients.

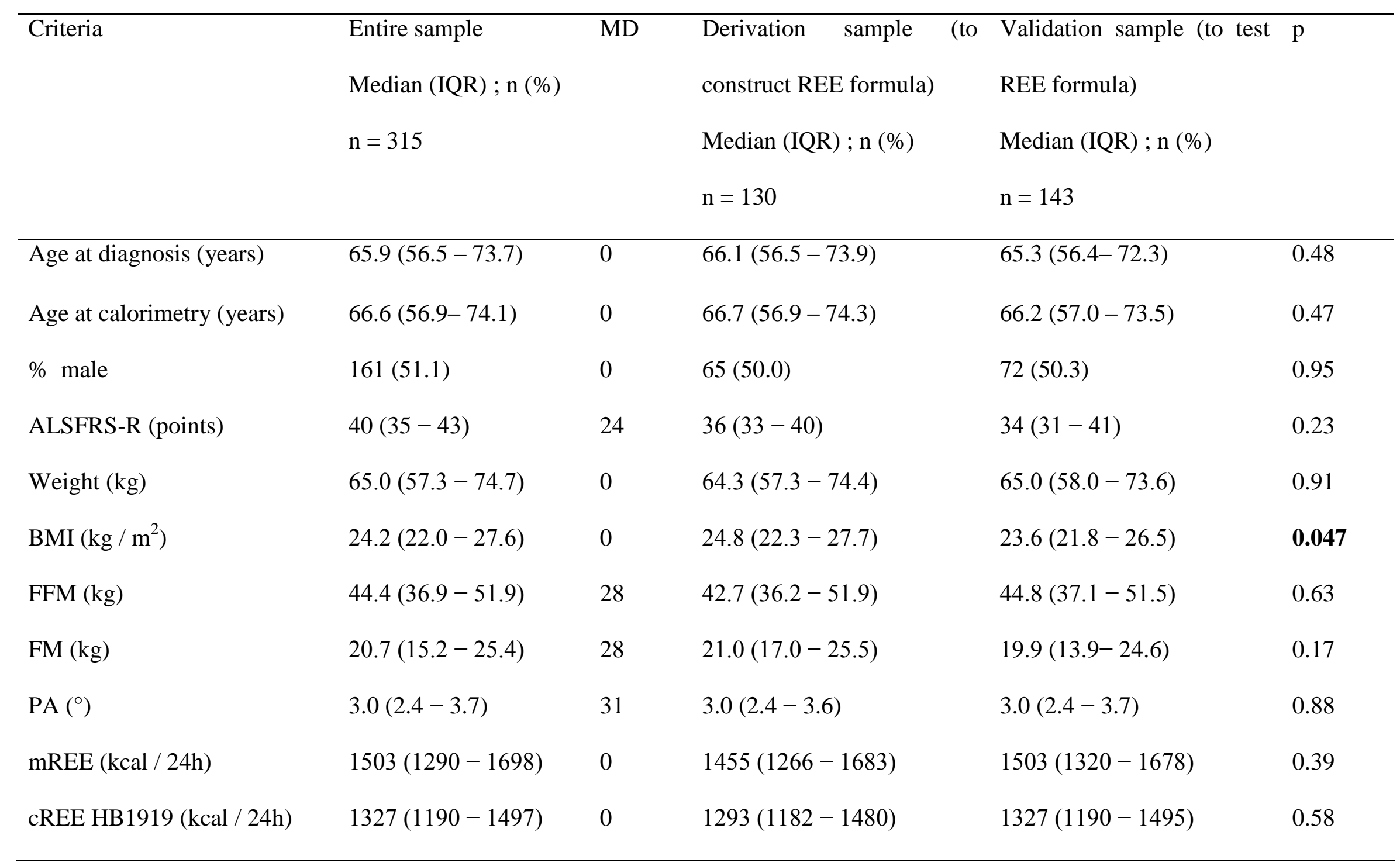




\begin{tabular}{llllll}
\hline cREE HB1984 (kcal / 24h) & $1355(1213-1511)$ & 0 & $1338(1215-1500)$ & $1356(1213-1489)$ & 0.69 \\
cREE WSchofield (kcal / 24h) & $1350(1217-1510)$ & 0 & $1380(1214-1500)$ & $1345(1230-1500)$ & 0.95 \\
cREE De Lorenzo (kcal / 24h) & $1361(1203-1528)$ & 0 & $1346(1191-1521)$ & $1364(1211-1503)$ & 0.72 \\
cREE Johnstone (kcal / 24h) & $1317(1158-1485)$ & 28 & $1298(1145-1481)$ & $1326(1161-1462)$ & 0.73 \\
cREE Mifflin (kcal / 24h) & $1286(1085-1453)$ & 0 & $1289(1055-1445)$ & $1273(1105-1438)$ & 0.59 \\
cREE WHO/FAO (kcal / 24h) & $1378(1256-1567)$ & 0 & $1367(1238-1553)$ & $1385(1275-1552)$ & 0.55 \\
cREE Owen (kcal / 24h) & $1434(1221-1610)$ & 0 & $1435(1221-1617)$ & $1422(1222-1577)$ \\
cREE Fleisch (kcal / 24h) & $1392(1242-1524)$ & 0 & $1386(1222-1520)$ & $1386(1259-1505)$ & 0.83 \\
cREE Wang (kcal / 24h) & $1268(1082-1451)$ & 28 & $1226(1065-1451)$ & $1277(1088-1441)$ & 0.59 \\
cREE Rosenbaum (kcal / 24h) & $1362(1232-1509)$ & 28 & $1355(1230-1514)$ & $1369(1233-1472)$
\end{tabular}

BMI: body mass index; FFM: fat-free mass; FM: fat mass; HB: Harris \& Benedict; IQR: interquartile range; Mifflin: Mifflin St. Jeor; PA: phase angle; mREE: measured resting energy expenditure; cREE: calculated resting energy expenditure; WHO/FAO: world health organization / food and agriculture organization of the United Nations; WSchofield: World Schofield. 
Table 3: Prediction of calculated resting energy expenditure with the 11 formulas compared to measured resting energy expenditure in the entire sample $(n=315)$. 


\begin{tabular}{|c|c|c|c|c|c|c|c|c|c|c|}
\hline \multirow[b]{2}{*}{$\begin{array}{c}\text { Mean } \\
\text { (kcal/24h) }\end{array}$} & \multirow[b]{2}{*}{ SD } & \multicolumn{2}{|c|}{ Bias } & \multicolumn{4}{|c|}{$95 \%$ limits of agreement } & \multicolumn{3}{|c|}{ Prediction } \\
\hline & & $\begin{array}{c}\text { C-M } \\
\text { (kcal/24h) }\end{array}$ & $\%$ & From & to & $\begin{array}{l}\text { between } \\
\text { limit }\end{array}$ & ICC $(95 \% \mathrm{CI})$ & $\begin{array}{l}\text { Accurate } \\
( \pm 10 \%) \\
(\%)\end{array}$ & $\begin{array}{l}\text { Under } \\
10 \% \\
(\%)\end{array}$ & $\begin{array}{l}\text { Over } \\
10 \% \\
(\%)\end{array}$ \\
\hline 1514 & 298.7 & - & - & - & - & - & & - & - & - \\
\hline 1356 & 229.2 & -158.4 & -9.4 & -498.2 & 181.5 & 94.9 & $0.67(0.18-0.84)$ & 45.1 & 51.7 & 3.2 \\
\hline 1377 & 223.3 & -136.8 & -7.9 & -473.1 & 199.6 & 95.2 & $0.70(0.30-0.84)$ & 49.8 & 45.4 & 4.8 \\
\hline 1385 & 215.3 & -129.0 & -7.1 & -491.6 & 233.6 & 95.6 & $0.67(0.35-0.81)$ & 43.5 & 43.8 & 6.7 \\
\hline 1377 & 235.8 & -136.9 & -8.1 & -467.0 & 193.1 & 95.9 & $0.71(0.30-0.86)$ & 50.2 & 45.4 & 4.4 \\
\hline 1332 & 236.8 & -181.0 & -11.1 & -512.6 & 150.7 & 94.4 & $0.66(0.06-0.85)$ & 36.9 & 60.3 & 2.8 \\
\hline 1283 & 252.1 & -231.5 & -14.8 & -560.3 & 97.4 & 95.6 & $0.60(-0.07-0.84)$ & 27.3 & 71.4 & 1.3 \\
\hline 1420 & 222.9 & -94.2 & -4.9 & -456.0 & 267.7 & 96.2 & $0.71(0.54-0.81)$ & 54.9 & 33.7 & 11.4 \\
\hline 1428 & 218.7 & -86.1 & -4.3 & -447.6 & 275.3 & 95.9 & $0.71(0.57-0.80)$ & 57.5 & 31.7 & 10.8 \\
\hline 1392 & 197.5 & -122.4 & -6.7 & -465.2 & 220.4 & 94.9 & $0.68(0.36-0.82)$ & 54.0 & 40.0 & 6.0 \\
\hline 1284 & 245.7 & -229.3 & -14.3 & -607.7 & 149.1 & 95.8 & $0.56(-0.03-0.80)$ & 32.1 & 65.5 & 2.4 \\
\hline 1378 & 196.9 & -135.2 & -7.4 & -504.1 & 233.8 & 94.8 & $0.64(0.30-0.79)$ & 46.7 & 46.0 & 7.3 \\
\hline
\end{tabular}


CI: confidence interval; C-M: calculated REE minus measured REE; HB: Harris \& Benedict; ICC: intraclass correlation coefficients; IQR: interquartile range; Mifflin: Mifflin St. Jeor; PA: phase angle; REE: resting energy expenditure; cREE: calculated resting energy expenditure; SD: standard deviation; WHO/FAO: world health organization / food and agriculture organization of the United Nations; WSchofield: World Schofield. 
Table 4: Prediction of calculated resting energy expenditure with the 11 formulas and the constructed formula compared to measured resting energy expenditure in the validation sample $(n=143)$.

\begin{tabular}{|c|c|c|c|c|c|c|c|c|c|c|}
\hline \multicolumn{2}{|c|}{ REE } & \multicolumn{2}{|c|}{ Bias } & \multicolumn{3}{|c|}{$95 \%$ limits of agreement } & \multirow[b]{2}{*}{ ICC $(95 \% \mathrm{CI})$} & \multicolumn{3}{|c|}{ Prediction } \\
\hline $\begin{array}{c}\text { Mean } \\
\text { (kcal/24 } \\
\text { h) }\end{array}$ & $\mathrm{SD}$ & $\begin{array}{c}\text { C-M } \\
(\mathrm{kcal} / 24 \mathrm{~h})\end{array}$ & $\%$ & From & to & $\begin{array}{c}\% \text { between } \\
\text { limits }\end{array}$ & & $\begin{array}{c}\text { Accurate } \\
( \pm 10 \%) \\
(\%)\end{array}$ & $\begin{array}{c}\text { Under } 10 \% \\
(\%)\end{array}$ & $\begin{array}{c}\text { Over } 10 \% \\
(\%)\end{array}$ \\
\hline 1514 & 373.2 & - & - & - & - & - & & - & - & - \\
\hline 1356 & 222.2 & -158.1 & -9.6 & -497.8 & 181.5 & 95.1 & $0.70(0.20-0.86)$ & $45.5^{*}$ & $51.0 *$ & $3.5^{*}$ \\
\hline 1375 & 212.8 & -139.3 & -8.2 & -473.4 & 194.8 & 95.1 & $0.72(0.32-0.87)$ & $49.7 *$ & $46.2 *$ & $4.2 *$ \\
\hline 1381 & 207.1 & -133.7 & -7.7 & -493.1 & 225.7 & 97.2 & $0.69(0.38-0.83)$ & $49.0 *$ & $45.5^{*}$ & $5.6^{*}$ \\
\hline 1376 & 224.9 & -138.4 & -8.3 & -465.0 & 188.2 & 95.1 & $0.74(0.30-0.88)$ & $51.7 *$ & $44.8^{*}$ & $4.9 *$ \\
\hline 1326 & 215.5 & -187.9 & -11.6 & -516.5 & 140.7 & 95.1 & $0.70(0.05-0.88)$ & $34.3 *$ & $62.9 *$ & $2.8^{*}$ \\
\hline 1285 & 241.6 & -229.4 & -14.7 & -561.2 & 102.4 & 95.1 & $0.62(-0.07-0.86)$ & $26.6^{*}$ & $71.3^{*}$ & $2.1 *$ \\
\hline 1421 & 213.2 & -93.7 & -5.1 & -443.1 & 255.6 & 97.2 & $0.68(0.48-0.80)$ & 55.2 & $34.3^{*}$ & 10.5 \\
\hline 1418 & 206.9 & -96.2 & -5.1 & -464.6 & 272.3 & 95.8 & $0.65(0.45-0.77)$ & 56.6 & $33.6^{*}$ & 9.8 \\
\hline 1398 & 189.0 & -120.9 & -6.8 & -448.8 & 207.0 & 95.1 & $0.66(0.31-0.81)$ & 55.9 & $39.9 *$ & $4.2 *$ \\
\hline
\end{tabular}




$\begin{array}{lccccccccccccc}\text { cREE Wang } & 1281 & 224.0 & -233.5 & -14.5 & -618.9 & 151.8 & 95.8 & 0.48(-0.06-0.75) & 30.1^{*} & 66.6^{*} & 3.5^{*} \\ \text { cREE Rosenbaum } & 1369 & 178.0 & -145.0 & -8.2 & -500.1 & 210.2 & 95.1 & 0.58(0.17-0.77) & 43.4^{*} & 50.3^{*} & 6.3 * \\ \text { cREE Constructed Formula } & 1492 & 236.3 & -21.6 & -0.5 & -347.7 & 304.4 & 95.1 & 0.85(0.79-0.89) & 65.0 & 17.5 & 17.5\end{array}$

*: comparison cREE CF vs other cREE formulas $\mathrm{p}<0.05$

CI: confidence interval; C-M: calculated REE minus measured REE; HB: Harris \& Benedict; ICC: intraclass correlation coefficients; IQR: interquartile range; Mifflin: Mifflin St. Jeor; PA: phase angle; REE: resting energy expenditure; cREE: calculated resting energy expenditure; SD: standard deviation; WHO/FAO: world health organization / food and agriculture organization of the United Nations; WSchofield: World Schofield. 
Table 5: Studies on patients with amyotrophic lateral sclerosis with measured and calculated resting energy expenditure and bias.

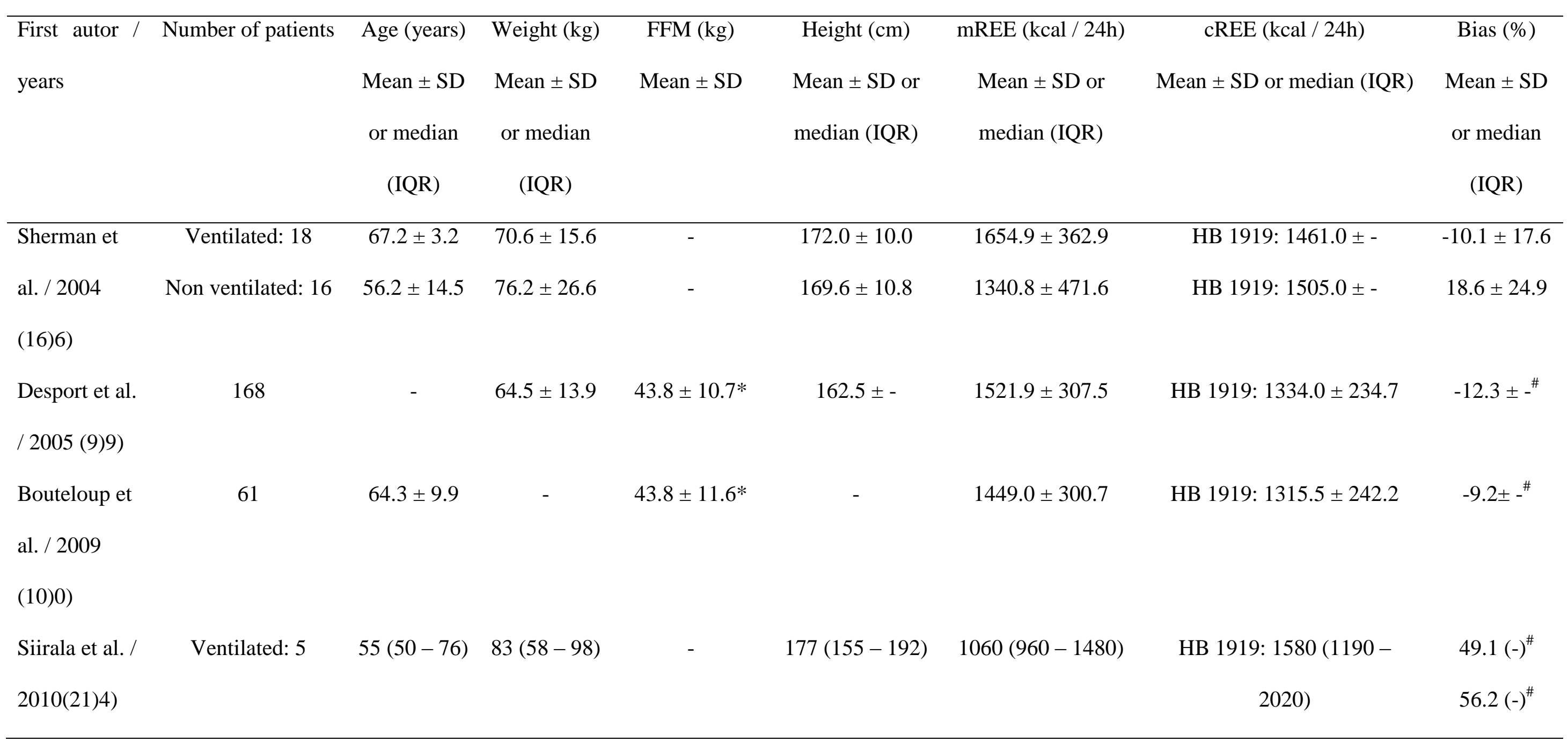


WHO/FAO: 1656 (1374 -

2039)

Mifflin: 1557 (1399 - 1909)

Owen: $1726(1183-1879)$

Fleisch: $1630(1210-1938)$

Kasarskis et

$58.7 \pm 11.9$

$80.1 \pm 16.8$

$50.7 \pm 11.1^{*}$

$171.9 \pm-$

$1539.0 \pm 366.0$

HB 1919: $1596.0 \pm 283.0$

Mifflin: $1523.0 \pm 283.0$

Rosenbaum: $1508.0 \pm 203.0$

Wang: $1315.0 \pm 264.0$

Owen: $1589.0 \pm 250.0$
$46.9(-)^{\#}$

$62.8(-)^{\#}$

$53.8(-)^{\#}$

$3.7 \pm-^{\#}$

$-1.0 \pm-^{\#}$

$-2.0 \pm-^{\#}$

$-14.6 \pm-^{-}$

$3.2 \pm-^{\#}$

\# Bias not calculated in the study, a posteriori calculation with mean or median cREE and mREE.

FFM: fat-free mass (*: in bioimpedance analysis); HB: Harris and Benedict; IQR: interquartile range; Mifflin: Mifflin St. Jeor; REE: resting energy expenditure; mREE: measured resting energy expenditure; cREE: calculated resting energy expenditure; SD: standard deviation; WHO/FAO: world health organization / food and agriculture organization of the United Nation. 